\title{
O Projeto Político Pedagógico do curso de Estatística da Universidade Federal do Rio Grande do Sul: uma análise do Plano de Desenvolvimento Institucional da UFRGS
}

\author{
The pedagogical political project of the statistics of the statistics course of the \\ Federal University of Rio Grande do Sul: an analysis in relation to the \\ Institutional Development plan at UFRGS
}

\author{
Michele da Silva Nimeth Riella ${ }^{1}$ \\ Ana Cristina Ghisleni ${ }^{2}$
}

\begin{abstract}
RESUMO
O estudo destaca aspectos do Projeto Pedagógico do curso de Bacharelado em Estatística da Universidade Federal do Rio Grande do Sul (UFRGS) do ano de 2017, considerando seu alinhamento com o Projeto Pedagógico Institucional (PPI) contemplado no Plano de desenvolvimento Institucional (PDI) da Universidade (2016-2026). Identifica elementos relevantes que reforçam a conectividade da gestão a um modelo educacional democrático, social e igualitário, pois, ao relacionar os dois documentos, torna-se possível identificar pontos de interseção em vários aspectos pedagógicos e de gestão. O artigo se utiliza do método qualitativo, que se dedica as questões que não podem ser quantificadas, focandose na compreensão e explicação das interações sociais existentes (GERHARDT; SILVEIRA; 2009), utilizando como técnica a pesquisa documental.
\end{abstract}

Palavras-chave: Projeto político-pedagógico; Gestão da educação superior; Gestão pedagógica.

\begin{abstract}
This study highlights aspects of the pedagogical project of The Bachelor of Statistics course of the Federal University of Rio Grande do Sul (UFRGS), from the year 2017, considering its alignment with the institutional Pedagogical Project (PPI) contemplated in the plan of Institutional development (PDI) of the University (2016-2026). It identifies relevant elements that reinforce the connectivity of management to a democratic, social, and egalitarian educational model because, when relating the two documents, it becomes possible to identify points of intersection in various pedagogical and management aspects. The article uses the qualitative method, which focuses on the questions that cannot be quantified, focusing on understanding, and explaining the existing social interactions. GERHARDT SILVEIRA 2009), using documentary research as a technique.
\end{abstract}

Keywords: Political-pedagogical project; Higher education management; Pedagogical management.

\footnotetext{
${ }^{1}$ Mestranda em Gestão Educacional pela Universidade do Vale do Rio dos Sinos - Unisinos. Administradora da Pró-Reitoria de Pesquisa da Universidade Federal do Rio Grande do Sul (UFRGS). Email: michele.riella@propesq.ufrgs.br.

${ }^{2}$ Professora pesquisadora do Programa de Pós-Graduação em Gestão Educacional - Mestrado Profissional da Universidade do Vale do Rio dos Sinos (Unisinos). E-mail: acghisleni@ unisinos.br.
} 
O presente estudo tem como objetivo identificar e analisar alguns aspectos do Projeto Pedagógico do curso de Bacharelado em estatística do Instituto de Matemática e Estatística da Universidade Federal do Rio Grande do Sul (UFRGS) do ano de 2017 , considerando seu alinhamento com o Projeto Pedagógico Institucional (PPI) contemplado no Plano de desenvolvimento Institucional (PDI) da Universidade (2016-2026). Além de identificar elementos relevantes que reforçam a conectividade da gestão ao um modelo educacional democrático, social e igualitário. Destaca-se, ainda, a importância de esclarecer que o PDI, segundo Decreto $\mathrm{n}^{\circ} 5.773$, de 9 de maio de 2006, adentra o campo estratégico, cujo documento apresenta a missão, as metas e os objetivos da organização em todos os âmbitos, sejam eles da gestão e do pedagógico. Já o projeto pedagógico do curso de Estatística, elaborado em conformidade com as Diretrizes Curriculares do Curso de Graduação em Estatística, estabelecidas na Resolução no 8, de 28/11/2008 da Câmara de Educação Superior do Conselho Nacional de Educação, possui um viés pedagógico, além de explicitar como é o funcionamento do curso, as expectativas quanto ao egresso e às características do curso. Entendo que, ao relacionar esses dois documentos, é possível identificar várias características tanto da gestão quanto do pedagógico que contemplam pontos de intersecção.

$\mathrm{O}$ artigo se utilizará do método qualitativo, que se dedica às questões que não podem ser quantificadas, fo- cando-se na compreensão e explicação das interações sociais existentes (GERHARDT; SILVEIRA; 2009). Já do ponto de vista de Flick (2009), a pesquisa qualitativa tem uma importância peculiar no campo das relações sociais considerando a pluralização no âmbito da vida. $\mathrm{O}$ autor também ressalta que, diante da mudança social desenfreada e da constante diversificação de esfera de vida, cada vez mais os pesquisadores sociais se deparam com novos contextos e concepções sociais. Além disso, utilizaremos como técnica a pesquisa documental que faz uma análise do PDI da UFRGS e do Projeto pedagógico do curso de bacharelado em estatística, ambos documentos publicados, respectivamente, no ano de 2016 e 2017. Sendo assim, o presente estudo está estruturado da seguinte forma: primeiramente mostraremos o referencial teórico em que é destacado o papel do diretor, do educador e do sistema educacional; em um segundo momento, traremos algumas características do PDI da UFRGS. Após, será apresentada uma análise considerando as Políticas de Ensino estabelecidas no documento PDI da UFRGS, o Projeto Pedagógico do Curso de Estatística e o referencial teórico e, por fim, as considerações finais.

\section{Qual modelo de educação que queremos?}

O Brasil é fortemente marcado pelo modelo autoritarista, o que o torna um país com grandes desigualdades nos aspectos sociais, econômicos e culturais. Podemos dizer que já houve 
efetivos avanços até o momento, inclusive em termos de direitos, principalmente nas últimas décadas, porém há muito que fazer ainda. Nesse sentido, quanto ao sistema educacional a situação não é diferente, o modelo autoritarista e burocrata predominou no meio educacional por muitos anos se enraizando no meio escolar, refletindo na maneira de fazer gestão na educação. Contudo, é fundamental refletirmos sobre a prática do diretor escolar, e de como essa direção atua e de que forma esse gestor vislumbra o Projeto Político Pedagógico da escola. Cabe ressaltar que o diretor é um agente político que tem como fim prover a educação de excelência através de ações democráticas e públicas, dando espaços para a participação da comunidade escolar. Além disso, no modelo democrático, quando o gestor abarca o interesse de seus liderados, certamente ele ganha maior legitimidade na sua gestão, não agindo meramente como um burocrata. É perceptível a necessidade de reformulações no formato de gestão escolar que está diretamente vinculada à concepção de como a educação é praticada no ambiente de ensino. Contudo, é necessário contemplar na gestão escolar as especificidades do processo pedagógico em uma dimensão democrática como prática social e política (PARO, 2010).

Importante ressaltar que o papel do diretor em escola tem uma função de zelar por melhor acomodação dos meios aos fins diante do trabalho realizado por uma coordenação, considerando a dedicação do coletivo, além de responsabilidade pelo bom andamento da organização. Assim, teori- camente, podemos dizer que o diretor de uma escola nos remete ao diretor de empresa de produção capitalista? Se igualarmos a figura do diretor de escola a um diretor de uma empresa em que o objetivo essencial é o lucro, verificaremos que há diferenças nos objetivos (fim) dessas organizações, além da forma de alcançá-los (meio). Nesse sentido, é preciso trazer à tona e questionar qual é a atividade-fim da escola e da educação? Independentemente do nível educacional, deve-se compreender se ele é de fato realizável e desejável. Na realidade, o que acontece no sistema de ensino e na implementação de políticas públicas educacionais é a redução da concepção de educação, resumindo-se apenas na transferência de conhecimentos e de conteúdo. O que diverge da Lei, que coloca como finalidade da educação o pleno desenvolvimento do estudante, além de prepará-lo para exercer a cidadania e qualificá-lo para o mercado de trabalho. Contudo, a educação é crucial na formação do ser humano, considerando sua historicidade e a propagação para as gerações futuras, podendo haver mutações significativas ao longo do percurso. Contudo, a relevância de obtermos uma educação plena, incluindo elementos culturais, como os valores, métodos, ciência, arte, esportes, as crenças, os costumes, a sociologia, a filosofia, os costumes, dentre outros, dão o sentido pleno a concepção de educação (PARO, 2010).

A identidade do homem e sua história somente se forma a partir da educação e, por isso, o processo pedagógico deve ser uma vertente essencial e definidora, inclusive da personalida- 
de do educando, considerando que o objetivo final da educação é a formação do sujeito, diante da cultura absorvida. Contudo, é preciso estar atento às condições em que este educando se constrói como sujeito e como faz a apropriação do seu aprendizado, sendo necessário considerar nesse processo questões de ordem biopsíquicas, sociais, além de conhecer o indivíduo desde seu nascimento (PARO, 2010).

Além disso, cabe frisar que a vontade de querer aprender não é qualidade inata, e, sim, um processo construído ao longo do tempo, considerando que essa vontade de querer e a curiosidade de aprender são peças fundamentais no aprendizado do sujeito, inclusive colocadas como um maior desafio da pedagogia até hoje. O que não pode acontecer é a educação ser tratada como uma atividade trivial, sem o saber necessário e a competência adequada para atuar nesse processo que ultrapassa questões de ordem técnica do profissional educador, pois deve ser uma relação que envolva também o viés político, em que o educador e o educando estabelecem parceria e consentimento mútuo, podendo ser chamado de relação democrática. Porém, mesmo que esta concepção de ação pedagógica tenha sido comprovada, cientificamente, diante sua eficácia no processo de ensinopedagógico, infelizmente, ainda não surtiu efeitos de fato nas organizações escolares que ainda se sustentam apenas de programas e currículos, fazendo com que o ensino se torne engessado e reduzido em um formato em que professor é um mero transmissor de conteúdo, empobrecendo a função do educador. Dessa forma, a figura do professor pode, tranquilamente, ser substituída por vídeos educativos através do computador, havendo apenas a transmissão de conhecimento, sendo descartados todos os elementos culturais relevantes para a formação do sujeito (PARO, 2010).

Se por um lado há uma omissão do sistema educacional por fomentar uma educação plena, por outro, há também uma administração arcaica infiltrada até hoje nos espaços educacionais, inserida de forma inapropriada para se atingir o objetivo das organizações de ensino. Inclusive, quando a educação era destinada apenas para a elite, a questão era abafada, considerando que a cultura já fazia parte do seio familiar e social desses jovens e crianças. Assim, a escola se responsabilizava apenas com uma parte da educação, incumbindo-se apenas em "transmitir o conhecimento". O sistema de ensino, além de desenvolver uma função muito limitada, ainda tinha como característica a exclusão, pois aqueles estudantes que não acompanhavam o padrão eram reprovados e culpabilizados por todo fracasso existente. Ressalta-se que esse novo contexto causa um mal-estar na escola que não consegue mais se esquivar por detrás de um segmento, entretanto é importante frisar que a educação é um dever constitucional para todos, independente da classe social (PARO, 2010).

Outro aspecto que trago é a forte presença de uma lógica empresarial capitalista nas políticas de gestão escolar. Essa concepção, inclusiva, ganha um grande espaço na atuação do dire- 
tor. Esse mesmo modelo é culturalmente aceito pela sociedade, prevalecendo a submissão e o controle. No entanto, no modelo democrático, a autoridade tem outra significação em que há a concordância e conscientização entre as partes envolvidas. Assim, a negação desse viés democrático deve ser lida como um autoritarismo, modelo que prepondera nas práticas do sistema escolar, em que coordenação do esforço humano coletivo é exercida apenas por uma pessoa que, no caso, é o diretor. Esse processo baseia-se em normas vindas de poder externo, sem a participação e/ou a concordância em que se tem o dever de obedecer. Assim, professores e educadores acostumam-se com esse formato vertical, em que alguém dá ordem e alguém recebe, passivamente, sem nenhuma interferência. Entretanto, cabe ressaltar que a relação formadora humana-histórica requer relações democráticas que se configuram na constituição do sujeito, refletindo na sua forma de tratar o outro. Por isso, é tão difícil exercer uma educação de excelência na sociedade, visto que há ainda a predominância muito forte do modelo autoritarista.

Ainda hoje, os sistemas educacionais ainda funcionam de forma excludente, entendendo que, dessa forma, solucionam o fracasso escolar. No entanto, o que acontece de forma muito frequente, até hoje, é que, quando o aluno não consegue acompanhar e não possui um desempenho satisfatório dentro do padrão de avaliação, a escola decide pela repetição de todo o nível. Essa decisão, além gerar um atraso temporal na sua vida escolar, também reflete em grandes sequelas psicológicas, pois o aluno terá que lidar com o sentimento de exclusão e inferioridade diante de um determinado grupo o qual fazia parte até o momento. Essa conduta da escola produz a desigualdade, a diferença e a exclusão, pois gerará certamente naquele jovem um sentimento imensurável relacionado à incapacidade e à baixa autoestima que pode interferir na sua personalidade e na sua identidade como sujeito. Cabe destacar ainda que a desigualdade não advém da escola e nem da sociedade, mas da relação entre o que se espera do aluno e os recursos culturais que cada um dispõe e sabe utilizar (THURLER; MAULINI, 2012).

Thurler e Maulini (2012) ressaltam que o professor deve ser ativo em sala de aula, gerindo diferentes situações, através de ações coletivas de trabalho com o próprio aluno, ou seja, envolver os alunos nos processos de ensino aprendizagem, como as práticas intelectuais, nos processos de pesquisas, de escrita e a análise dos dados e das informações. No entanto, o que permeia o sistema de ensino ainda é o modelo de gestão escolar burocratizada que reflete, inclusive, na atuação do professor em sala de aula com alunos. Atualmente, vivemos em formato de ensino que alunos são colocados em uma situação de comando sob controle do professor, sem nenhuma forma de participação e protagonismo em sala de aula. Já os professores, por sua vez, são passivamente comandados por um conjunto de exigências e de injunções pré-estruturantes das ações baseadas em normas e prescrições. 
Há uma lacuna entre o trabalho real e o trabalho prescritivo. Nesse espaço, podemos perceber uma margem de manobra e pode ser consciente ou não, mas que pode ser uma oportunidade para se fazer mais ou menos do que é mandado ou prescrito. Além disso, o ambiente em que se dá os sistemas de educacionais, suas normativas de excelência, seus critérios de justiça, sua política e o contexto social e sua história possui efeitos e comportamentos decisivos nas práticas e das intenções voltada para mudanças dos profissionais educadores, tanto de ordem individual como coletiva. Na verdade, a organização do trabalho se tornou um grande desafio, inclusive, há estudos com laboratórios de inovação e formação e educação que estudam a maneira na qual as escolas evoluem e como emergem e se discutem, ou seja, inovam-se. Além disso, estudos mostram que a excelência escolar não é algo a se constatar, mas a se questionar e a se confrontar, em que se conduz o maior número de alunos a competências compartilhadas. Contudo, estudos mostram, antes de tudo, a maneira como a escola se organiza, regulariza, estimula sua pedagogia faz toda a diferença no sistema educacional, em que o problema não fica apenas no âmbito da pedagogia, mas principalmente na forma de organizar o trabalho e de geri-lo. Claro, requer um esforço e aprendizagem da escola que aos poucos vai verificando outras formas de organizar, abandonando um funcionamento conhecido para adentrar em um contexto mais flexível e complexo. Essa situação causa uma perturbação em todos que estão acos- tumados a viver na zona de conforto, obrigando a reconstruir novos modos de atuação em sala de aula, novas formas de avaliação, de gestão de classe, do comportamento diante do aluno e da comunidade escolar. Enfim, vão surgir resistências diante de um contexto menos familiar e com maiores incertezas (THURLER; MAULINI, 2012).

Outro ponto importante a ser colocado é o poder da globalização que reflete significativamente nas políticas, na cultura e na economia, em que há interesses de grandes empresas e organismos, trazendo grandes repercussões na educação. No caso do ensino superior, é possível perceber que a formação de alunos é voltada para a capacitação somente para o emprego, em que o critério principal do valor do conhecimento é a utilidade para crescimento e desenvolvimento do mercado. Assim, vivenciamos hoje a pobreza da globalização moral, da justiça social e dos projetos de construção civilizacional, em que há a desconstrução do conhecimento focado na elevação espiritual humano, na formação de um cidadão ciente de suas responsabilidades, sendo capaz de construir uma sociedade justa e igualitária (SOBRINHO, 2018).

\section{O Plano de Desenvolvimento Institucional (PDI) da UFRGS (2016-2026)}

Importante frisar que o PDI do ano de 2011 a 2015 foi o primeiro instrumento de gestão institucional construído de forma participativa, envol- 
vendo toda a comunidade acadêmica. O documento foi, sem dúvida, um norteador da gestão acadêmica e administrativa da UFRGS, em que se obteve experiência por meio de uma metodologia a partir de consultas à comunidade com o objetivo de qualificar o atendimento ao aluno e os processos avaliativos de gestão. Nesse sentido, podemos dizer que o PDI anterior teve um papel importante para o PDI atual, em que se teve um caminho construído, além da continuidade estabelecida.

O atual PDI considera o cenário global e o constante desenvolvimento das novas tecnologias, das mudanças de hábito, da cultura da população, das comunicações e dos transportes, que traz grandes impactos para as organizações e para a sociedade. Assim, existe uma consciência da universidade quanto à relevância do dinamismo, da flexibilidade e da inovação. Outro aspecto importante é o reconhecimento do espaço universitário, em que o processo de aprender para aprender se torna essencial, além de repensar seus ideais acadêmicos e suas parcerias. O PDI é fruto de construção por meio de consultas públicas, conferências, seminários e palestras técnicas o qual refletiu na geração de ideias definidoras para os próximos 11 (onze) anos futuros, resultando em objetivos estratégicos alinhados ao conjunto de ações e metas do Plano Nacional de Educação (PNE) que orienta as linhas e ações da educação nacional.

O documento ressalta alguns aspectos que, hoje, são prioridade tanto na gestão administrativa quanto para o meio acadêmico. $\mathrm{O}$ primeiro menciona a transversalidade acadêmica como novas formas de atuação e de projetar o pedagógico, bem como o ambiente acadêmico institucional baseado na política de ensino, pesquisa e extensão. Outro ponto é a inovação curricular baseada na flexibilidade na formação, que prioriza a interdisciplinaridade, além do fomento dos novos programas e projetos e de integração de alunos em todos os níveis. E, por fim, foca na qualidade das ações acadêmicas e pedagógicas, tendo como fundamental o respeito aos direitos humanos, a sustentabilidade socioambiental, a valorização da diversidade, a inclusão e a valorização dos profissionais que atuam na educação.

\section{Políticas de ensino: a relação existente entre o PPI e o Projeto Pedagógico do curso Estatística}

Assim, para fazer esta averiguação documental, estabelecemos quatro (4) aspectos extraídos das políticas de ensino constantes do PPI que servirão de base para analisar o projeto político pedagógico do curso. Tais aspectos são: a interdisciplinaridade, a internacionalização, a inserção da Universidade na sociedade e a excelência na aprendizagem. Esses elementos são colocados como eixos fundamentais da instituição e devem ser desenvolvidos em todas as unidades de ensino, independente da área do conhecimento. Sendo assim, na primeira coluna do quadro a seguir, apresentamos os aspectos relacionados à política de ensino do PPI (UFRGS). Já na segunda 
coluna, serão abordados elementos do Projeto Pedagógico do Curso de Estatística (UFRGS) que se correlacionam com os elementos elencados da política de ensino do PPI.

\section{Quadro 1 - A relação entre os Aspectos relacionados a Políticas de Ensino do PPI e o Projeto Pedagógico do Curso de Estatística}

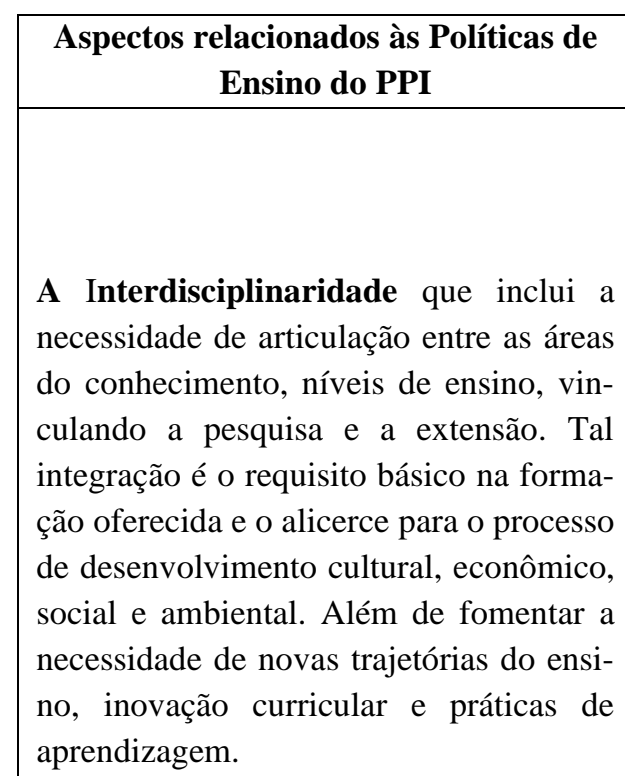

A Internacionalização permanece sendo um dos principais valores de excelência da Universidade de atuação política e acadêmica, em que se dá, fundamentalmente, através das relações de cooperação bilateral, multilateral com os institutos e internacionais. Além disso, cabe ressaltar a o programa de mobilidade acadêmica que inclui docentes, discente e técnicos administrativos.

A inserção da Universidade na Sociedade com a articulação do ensino com a produção do conhecimento por meio de ações e de pesquisas científicas, tecnológicas, artísticas e culturais. Além de permanecer com a promoção de política de inserção em todos os segmentos da sociedade, contemplando a ocupação plena de vagas oferecidas na graduação e na pós-graduação. Outro ponto importante é a aplicação do conhecimento produzido para a entrega de valor a sociedade, considerando também as políticas inclusivas.

\section{O Projeto Pedagógico do Curso de Estatística}

O profissional estatístico deve ser capaz de atuar em equipe multidisciplinar, contemplando todas as áreas do conhecimento, oferecendo suporte metodológico. Contudo, o programa do curso oferece uma ampla formação que inclui disciplinas diversas como estatística, matemática, administração, economia, ciências biológicas e humanas. Além disso, o documento ressalta que o egresso no curso reflete na multidisciplinaridade de conhecimentos que implicam em novas demandas da sociedade. Outro aspecto importante é que o curso faz a consolidação da formação acadêmica com o nível de mestrado e doutorado, oferecendo uma formação hibrida com área de estatística, facilitando a integração interdisciplinar de pessoas, conhecimentos e tecnologias. Portanto, o curso remete um viés em que há "tecnologia da ciência", havendo, assim, a articulação entre o ensino de graduação, pós-graduação de pesquisa, propiciando projetos de pesquisa e bolsa de iniciação científica.

Além de o curso ser reconhecido nacionalmente, também é internacionalmente. Destaquemos também o incentivo à mobilidade acadêmica, nacional e internacional na forma de intercâmbios, estágios e programas de dupla diplomação.

O curso objetiva qualificar o profissional para atuar tanto no meio acadêmico como no mercado de trabalho, considerando a relevância de ser ter uma profissional consciente de seu papel na sociedade de forma contribuir para uma sociedade democrática e igualitária. Outro ponto a destacar diz respeito às orientações oferecidas aos discentes, motivando a permanência, na tentativa de reduzir a evasão do curso. Ressalta-se também o esforço para a ocupação plena das vagas oferecidas, por meio de ingresso extravestibular. Por fim, destaca-se o acolhimento dos alunos com deficiência, com alguma necessidade específica cultural e dos que ingressam através das políticas de ações afirmativas. 


\begin{tabular}{|c|c|}
\hline $\begin{array}{l}\text { A Excelência de Aprendizagem com o } \\
\text { compromisso no atendimento das neces- } \\
\text { sidades pedagógicas do aluno, em que se } \\
\text { prioriza a formação integral, atendendo e } \\
\text { valorizando as diferenças individuais e } \\
\text { sociais, repercutindo no exercício social } \\
\text { e profissional. Outra ênfase, que inclusi- } \\
\text { ve foi colocada pela comunidade, é a } \\
\text { necessidade de novas práticas de apren- } \\
\text { dizagem. }\end{array}$ & $\begin{array}{l}\text { Incentivos aos alunos para que possam vivenciar e colabo- } \\
\text { rar com projetos de pesquisa e de pós-graduação. Outro } \\
\text { ponto é a busca de excelência na formação dos alunos, por } \\
\text { meio das trocas de experiências de pesquisa, além do ensi- } \\
\text { no de pós-graduação. Além do incentivo de uma postura } \\
\text { proativa do aluno para o ensino, pesquisa e extensão. Im- } \\
\text { portante ressaltar que o curso está atento ao aperfeiçoa- } \\
\text { mento, atualização e flexibilização do currículo, bem como } \\
\text { da integração de novas ferramentas e tecnologias, conside- } \\
\text { rando também a educação a distância como um meio de } \\
\text { atividade didática. }\end{array}$ \\
\hline
\end{tabular}

Fonte: Elaborado pelas autoras (2019).

Diante da relação do quadro, observa-se que há nitidamente um alinhamento entre os aspectos da política de ensino do PPI e o Projeto Pedagógico do Curso, considerando que os quatro (4) aspectos considerados foram de alguma forma contemplados no projeto pedagógico do curso. Importante destacar ainda que esses aspectos possuem um papel norteador e servem de diretrizes para as unidades acadêmicas estabelecerem os seus projetos pedagógicos. Assim, percebe-se com clareza que o curso de estatística atende a esses aspectos, que, por sua vez, desdobra essas diretrizes estabelecidas em ações a serem desenvolvidas, considerando as características e especificidades do curso.

\section{A análise dos dados e as considerações finais}

Ressalta-se a abrangência democrática que o PDI possui como ferramenta de gestão na Universidade que serve de base para todas as esferas educacionais, sejam elas no campo da pesquisa, do ensino e da extensão, além disso merece destaque a sua construção de caráter coletivo e con- sultivo diante da comunidade. Importante ainda frisar que, de acordo com Paro (2010), uma educação de excelência só se constrói a partir de ações democráticas e públicas, considerando a participação da comunidade escolar. Essa postura também traz reflexos para a legitimidade do gestor da organização, no caso da UFRGS, o Reitor demonstra estar atento às mudanças ocorridas na sociedade e seus anseios, possibilitando ajustes e a adaptação do instrumento quando necessário, refletindo na excelência educacional.

Percebe-se, também, que os documentos analisados buscam uma preocupação com a formação do aluno, considerando a interdisciplinaridade, abrangendo diversas áreas do conhecimento, as experiências e compartilhamentos com a pós-graduação, bem como com a extensão, incluindo até mesmo vivências em projetos de âmbito nacional e internacional, inclusive aqueles que contemplam bolsa de iniciação científica. Isso mostra o quanto a Universidade está empenhada para despertar no aluno a vontade de aprender, além disso traz à tona possibilidades para uma formação plena e qualificada, desenvolvendo um profissional 
ciente de suas responsabilidades na sociedade. Cabe frisar ainda que as diversas vivências e conhecimentos que a instituição proporciona ao aluno potencializam elementos culturais relevantes no processo da educação, como a criatividade, a inspiração, reflexões, novos saberes e a inovação, além de despertar os laços das relações interpessoais e que adentram os valores, os costumes, a ética dentre outros. Inclusive, nessa perspectiva, Paro (2010) nos confirma que o objetivo final da educação, seja ela em qualquer âmbito, é a formação do sujeito, diante da cultura que se retém. Além disso, Paro (2010) menciona que o querer aprender não é algo que acontece naturalmente, mas é um processo que necessita ser estimulado e construído.

Conforme Thurler e Maulini (2012), o sistema de ensino, além de desenvolver uma função muito limitada, ainda tinha como característica a exclusão, pois aqueles estudantes que não acompanhavam o padrão eram reprovados e culpabilizados por todo fracasso existente. Nessa perspectiva, no caso da UFRGS, percebe-se o empenho para tentar reduzir ou até mesmo eliminar a evasão no curso, diante de ações em prol da permanência do aluno. Além disso, podemos citar o acolhimento de alunos com deficiência e estudantes com alguma necessidade específica e dos que ingressam pela reserva de vaga oriunda das ações afirmativas. Destaca-se também a realização de extravestibular, quando necessário, a fim de fazer a ocupação de todas as vagas.
Thurler e Maulini (2012) colocam que, muitas vezes, o modelo de educação que vigora no sistema educacional é permeado pelo comando de professores que, por sua vez, são passivamente controlados por um conjunto de exigências e de uma estrutura baseada em normas e prescrições. Nesse sentido, observa-se que, por se tratar de uma universidade pública, é possível que os professores sejam cobrados por sua produção acadêmica dentro do quadro de avaliações externas regulares. Entretanto, percebe-se, por meio dos quatro (4) aspectos elencados no quadro acima, que há uma consciência da importância de se ter uma educação plena e uma formação de profissional que atenda às necessidades da sociedade e, por isso, a Universidade faz questão de obter e incentivar que o aluno seja proativo e protagonista, articulando o ensino, a pesquisa e a extensão, fortalecendo e enriquecendo ainda mais o ensino, um dos pilares fundamentais da Universidade. Além disso, cabe frisar ainda que Projeto Pedagógico do Curso de Estatística mostra-se atento e aberto para os aperfeiçoamentos necessários, bem como para atualizações e flexibilização do currículo. Essa postura é muito positiva, pois demonstra o quanto os gestores e professores estão sensíveis e cientes que a educação não é processo engessado e finalizado, mas sim um processo de construção contínua de aperfeiçoamento. Inclusive, nessa perspectiva, Thurler e Maulini (2012) nos mostram que, no processo de busca por novos caminhos, sejam eles nos 
modos de atuação em sala de aula ou em novas formas de fazer a avaliação do aluno, podem surgir resistências por parte dos educadores, pois toda a mudança gera incertezas e receios. Observa-se que, mesmo diante dessas resistências, a Universidade demonstra conhecer, por meio desses novos modos de fazer, contando principalmente com a participação e o protagonismo dos estudantes, a forma de se construir uma educação de excelência. Portanto, é importante ressaltar que, por meio dessas metodologias, atitudes e forma de pensar evidenciadas nos documentos institucionais seja possível deslumbrar um espaço permeado pela democracia, a partir da liberdade de pensamento e de expressão, em um ambiente plural, diverso e igualitário. 


\section{Referências}

BRASIL. Decreto $\mathbf{n}^{0}$ 5.773, de 9 de maio de 2006. Dispõe sobre o exercício das funções de regulação, supervisão e avaliação de instituições de educação superior e cursos superiores de graduação e sequenciais no sistema federal de ensino. Brasília, DF: Presidência da República, 2004. Disponível em: http://portal.mec.gov.br/seed/arqui vos/pdf/legislacao/decreton57731.pdf. Acesso em: 14 jun. 2019.

BRASIL. Lei no 13.005, de 25 de junho de 2014. Aprova o Plano Nacional de Educação - PNE e dá outras providências. Brasília, DF: Presidência da República, 2014. Disponível em: http://www.planalto.gov.br/ccivil_03/_ato2011 2014/2014/lei/113005. htm. Acesso em: 14 jun. 2019.

BRASIL. Resolução $\mathbf{n}^{\mathbf{0}}$ 8, de 28 de novembro de 2008. Institui as Diretrizes Curriculares Nacionais do curso de Estatística, de graduação plena, em nível superior, e dá outras providências. Brasília, DF: Ministério da Educação, 2008. Disponível em: http://portal.mec.gov.br/cne/arquivos/pdf/2008/rces008_08.pdf. Acesso em: 14 jun. 2019.

FLICK, Uwe. Introdução à pesquisa qualitativa. 3. ed. Porto Alegre: Artmed, 2009.

GERHARDT, Tatiana Engel; SILVEIRA, Denise Tolfo. Métodos de Pesquisa. Porto Alegre: UFRGS, 2009. E-book. Disponível em: http://www.ufrgs.br/cursopgdr/ downloadsSerie/derad005.pdf. Acesso em: 05 jul. 2019.

LOPEZ, Jesusa Rita Fidalgo Sanchez. Relação entre PDI, identidade institucional e gestão participativa nos Institutos Federais: desafios e possibilidades para o desenvolvimento. 2015. Dissertação (Mestrado em Gestão e Tecnologia Aplicadas à Educação). Universidade do Estado da Bahia, Salvador, 2015.

PARO, Vitor Henrique. A educação, a política e a administração: reflexões sobre a prática do diretor de escola. Educação e Pesquisa, São Paulo, v. 36, n.3, p. 763-778, set./dez. 2010. Disponível em: http://www.scielo.br/scielo.php?pid=S1517-9702201 $0000300008 \&$ script=sci_abstract\&tlng=pt. Acesso em: 16 out. 2019.

SOBRINHO, José Dias. Universidade em tempos ultraliberais. Avaliação, Campinas; Sorocaba, v. 23, n. 02, p. 288-293, jul. 2018. Disponível em: http://www.scielo.br/ pdf/aval/v23n2/1982-5765-aval-23-02-288.pdf. Acesso em: 16 out. 2019. 
THURLER, Monica Gather; MAULINI, Olivier (orgs.). A organização do trabalho escolar: uma oportunidade para repensar a escola. São Paulo: Penso, 2012.

UNIVERSIDADE FEDERAL DO RIO GRANDE DO SUL (UFRGS). Projeto pedagógico do curso de bacharelado em estatística: 2017. Porto Alegre: UFRGS, 2017. Disponível em: https://www.ufrgs.br/ime/wp-content/uploads/2017/09/ProjetoPedagogico-do-Curso-2017-1.pdf. Acesso em: 14 jun. 2019.

UNIVERSIDADE FEDERAL DO RIO GRANDE DO SUL (UFRGS). Plano de desenvolvimento institucional: PDI 2016-2026. Porto Alegre: UFRGS, 2016. Disponível em: http://www.ufrgs.br/pdi/PDI_2016a2026_UFRGS.pdf. Acesso em: 14 jun. 2019.

$O(s)$ autor(es) se responsabiliza(m) pelo conteúdo e opiniões expressos no presente artigo, além disso declara(m) que a pesquisa é original.

Recebido em 18/03/2020

Aprovado em 10/06/2020 